\title{
Influence of stress, temperature and crystal morphology on isothermal densification and specific surface area decrease of new snow
}

\author{
S. Schleef, H. Löwe, and M. Schneebeli \\ WSL Institute for Snow and Avalanche Research SLF, Davos, Switzerland \\ Correspondence to: H. Löwe (loewe@ slf.ch) \\ Received: 10 February 2014 - Published in The Cryosphere Discuss.: 31 March 2014 \\ Revised: 31 August 2014 - Accepted: 2 September 2014 - Published: 9 October 2014
}

\begin{abstract}
Laboratory-based, experimental data for the microstructural evolution of new snow are scarce, though applications would benefit from a quantitative characterization of the main influences. To this end, we have analyzed the metamorphism and concurrent densification of new snow under isothermal conditions by means of X-ray microtomography and compiled a comprehensive data set of 45 time series. In contrast to previous measurements on isothermal metamorphism on time scales of weeks to months, we analyzed the initial $24-48 \mathrm{~h}$ of snow evolution at a high temporal resolution of 3 hours. The data set comprised natural and laboratory-grown snow, and experimental conditions included systematic variations of overburden stress, temperature and crystal habit to address the main influences on specific surface area (SSA) decrease rate and densification rate in a snowpack. For all conditions, we found a linear relation between density and SSA, indicating that metamorphism has an immediate influence for the densification of new snow. The slope of the linear relation, however, depends on the other parameters which were analyzed individually to derive a best-fit parameterization for the SSA decrease rate and densification rate. In the investigated parameter range, we found that the initial value of the SSA constituted the main morphological influence on the SSA decrease rate. In turn, the SSA decrease rate constituted the main influence on the densification rate.
\end{abstract}

\section{Introduction}

The temporal evolution of new snow is delicate, since fast changes in bulk density or specific surface area (SSA) as key microstructural characteristics occur within hours after snowfall. Various applications rely on a quantitative understanding of these initial snowpack processes. For avalanche prediction, a fast or slowly densifying snowpack eventually discerns between conditions of high or low snowpack stability. Initial modeling uncertainties of the densification will propagate and persist through the entire season (Steinkogler et al., 2009). The density of snow is also important for hydrological applications, where estimates of snow-water equivalent are commonly obtained from snow-height measurements of meteorological stations via empirical correlations between height and density. The development of these parameterizations is complicated by intermediate snow falls and short time densification (McCreight and Small, 2014). If the state of the snowpack is instead monitored via remote sensing, the key quantity is snow albedo, which is mainly determined via SSA (Flanner and Zender, 2006). Even thin layers of new snow have a measurable impact on the total snow albedo (Perovich, 2007). Finally, the validation of winter precipitation schemes for meteorological models also relies on the connection between airborne crystal sizes (which might be related to the inverse SSA) and the bulk densities of new snow (Thompson et al., 2008).

For many applications, ground-truth measurements are not available, and the evolution of new snow on the ground must be addressed by snowpack modeling. Snowpack models primarily aim at a description of densification rates in terms of overburden and temperature (Jordan, 1991; Lehning et al., 2002; Vionnet et al., 2012). To cope with the needs of applications for metrics of crystal size and morphology, some of the models also include empirical, microstructural parameters, such as grain size, dendricity, sphericity or coordination 
number. The choice of these microstructural parameters is motivated by the natural variation of snow-crystal habits, plus some metric of connectivity. These empirical parameters are, however, ambiguous and cannot be measured objectively for aggregated snow. Therefore recent versions of snowpack models have replaced the empirical parameters by objective ones which can be uniquely defined for arbitrary bicontinuous structures. Of primary interest was the replacement of grain size by the SSA (or, more precisely, the optical radius) (Carmagnola et al., 2014) which is considered as the most important, morphological parameter of snow which can be measured in the field by various techniques.

Besides SSA, there is certainly a demand for higher-level morphological metrics to characterize snow microstructure. Various physical properties have been shown to be influenced by morphological characteristics beyond the SSA, e.g., thermal conductivity (Löwe et al., 2013) by anisotropy, the extinction of light (Libois et al., 2013) by grain shape, the scattering of microwaves by correlation lengths (Wiesmann et al., 1998) or confined compression of new snow by the Euler characteristic (Schleef et al., 2014b). The Euler characteristic is a topological metric for the connectivity of the structure (Michelsen et al., 2003). On the one hand, it might be regarded as a generalization of the grain-based concept of a coordination number (Lehning et al., 2002) to arbitrary threedimensional microstructures. On the other hand, the Euler characteristic is also exactly related to the average Gaussian curvature. The Euler characteristic thus constitutes a link to structure characterization in terms of full distributions of interfacial curvatures as a high-level morphological metric. This has, for example, recently been used to reveal details of temperature-gradient metamorphism (Calonne et al., 2014). These recent advances in microstructural insight are indeed necessary and important, but none of these higher-level morphological metrics have been implemented in snow models yet, not to mention the difficulties of measuring them by methods other than micro-computed tomography $(\mu \mathrm{CT})$. In the absence of advances to include or alternatively measure higher-level metrics, the density and the SSA must still be considered as the most important microstructural parameters for current snowpack models. A good representation of the time evolution of these parameters is a minimum requirement for these models. To reveal shortcomings of present models, there is a need to bridge the gap between laboratory-based techniques (e.g., $\mu \mathrm{CT}$ ) and field techniques in order to facilitate the validation of basic processes like metamorphism and densification under a wide range of environmental conditions.

From the perspective of laboratory experiments, some progress has recently been made in understanding the physical mechanisms underlying new snow densification and metamorphism within creep experiments (Schleef and Löwe, 2013). The results indicate that the evolution of the SSA occurs autonomously without being affected by the concurrent densification. The experiments were carried out for a sin- gle type of new snow obtained from a snowmaker at a single temperature (Schleef et al., 2014a). However, this small range of experimental conditions is only of limited use for the aforementioned applications and the validation of models. To cover a wide range of environmental conditions for snow types and temperatures, applications are interested in best-fit behavior of large data sets which are essential benchmarks to validate and drive snow-evolution models. From the perspective of field experiments, some data sets are available for well-aged seasonal snow (Domine et al., 2007) and data of experiments which include new snow in their first few days of evolution (Cabanes et al., 2002, 2003; Legagneux et al., 2003; Taillandier et al., 2007). However, comparable data from in situ experiments which monitor the evolution of the same sample of new snow at high temporal resolution are almost non-existent.

To fill this gap, we present a comprehensive data set of $\mu \mathrm{CT}$ experiments for new snow densification and metamorphism covering various examples of natural and laboratorygrown new snow with a wide range of initial crystal morphologies. The primary goal of the present work is to provide laboratory-based experimental data for validation purposes. Our aim is to bridge the gap between high-level laboratory experiments and the capabilities of field measurements by assessing whether densification and metamorphism under isothermal conditions can be described by the most important yet available parameters for snow models, namely the density, temperature, overburden stress and the SSA. We focus on the SSA as the most important morphological metric for snow microstructure. To relate to the original idea of crystal classification, we include a qualitative characterization of our experiments in terms of crystal-habit classes. To make contact with recent high-level morphological metrics, we also analyze the Euler characteristic.

The outline of the paper is as follows: in Sect. 2, we briefly summarize the methods for the experiments and the analyses which have been previously published elsewhere (Schleef and Löwe, 2013; Schleef et al., 2014a, b). We present in situ creep experiments at different temperatures and overburden stresses, and monitor the evolution of the main microstructural parameters, namely ice volume fraction $\phi_{\mathrm{i}}$ and SSA over 1 to 2 days at a temporal resolution of $3 \mathrm{~h}$. A reference experiment over an entire week indicates that this is sufficient in order to capture the main aspects of microstructural changes. The results of the experiments are given in Sect. 3. As an interesting generic result, we consistently find an almost linear relation between the density and the SSA, with different slopes, however, which depend on the specific conditions (Sect. 3.2). In the following, we separately discuss the influence of temperature (Sect. 3.3) and morphological characteristics (Sect. 3.4) on densification rate and SSA decrease rate. The different stress levels give rise to particularities which are pointed out. In Sect. 3.5, we address the combined effects of all parameters on densification rate and SSA decrease rate. Based on our generic relation between 
SSA and density, and based on previous modeling ideas, we derive simple parameterizations for the rate equation of SSA and density for new snow in terms of the most important yet available parameters, namely $\phi_{\mathrm{i}}$, SSA, temperature $T$ and stress $\sigma$. Our parameterization for the SSA is compared to an existing parameterization (Taillandier et al., 2007) in Sect. 3.6. Finally, we discuss our results in Sect. 4.

\section{Methods}

For a self-contained presentation we summarize the main steps of the method and outline differences or extensions to Schleef and Löwe (2013); Schleef et al. (2014a, b).

All snow samples were prepared from fresh snow which was either collected outside or produced with a machine in the cold laboratory (Schleef et al., 2014a), referred to as "natural snow" and "snowmaker snow", respectively. An overview of all sets of experiments with their main characteristics is given in Table 1. The natural snow was collected just outside the cold laboratory in Davos, Switzerland, during the winters of 2011/2012 and 2012/2013. To minimize previous metamorphism, only intense snowfalls at air temperatures below $-2{ }^{\circ} \mathrm{C}$ with a deposition time less than an hour were chosen. Immediately afterwards, the snow was sieved (mesh size $1 \mathrm{~mm}$ ) into sample holders of an $18 \mathrm{~mm}$ diameter with a $15 \mathrm{~mm}$ filling height. In between, photographs of sieved snow crystals were taken to capture the crystal habit. Each set of snow samples comprised several identically prepared samples which were stored in a freezer at $-60^{\circ} \mathrm{C}$. The storage conditions suppress metamorphism almost completely prior to the experiments (Kaempfer and Schneebeli, 2007). In total, eight sets of snow samples from different natural snow falls and six sets from different snowmaker runs were prepared (Table 1). In Schleef and Löwe (2013), the potential bias caused by different storage times was addressed. We found that no systematic change in the SSA and density during storage times of 3 weeks at $-60^{\circ} \mathrm{C}$ in the SSA range of around $70 \mathrm{~mm}^{-1}$ could be measured by $\mu \mathrm{CT}$. The storage influence observed for some samples (SSA: $\sim 2 \%$, density: $\sim 5 \%$ ) is generally small compared to the observed evolution during the experiments.

All experiments were conducted within a maximum of 3 weeks after sample preparation. The respective sample was placed in the cold laboratory 1 hour before the first measurement for thermal equilibration. For some experiments (Table 1), a cylindrical weight, corresponding to a stress of 133, 215 or $318 \mathrm{~Pa}$, respectively, was carefully put on the sample half an hour before starting the first measurement to analyze the influence of external stress. Stress values were chosen to mimic different potential burial depths of new snow inside the snowpack. The stress values correspond to burial depths of about $0-30 \mathrm{~cm}$, given an average new snow density of $100 \mathrm{~g} \mathrm{~m}^{-3}$.
The measurements were conducted with a computer tomograph ( $\mu$ CT 80, desktop system, SCANCO medical) operated in a cold laboratory at isothermal temperatures of about -13 or $-18^{\circ} \mathrm{C}$. For a single set (no. 14 , cf. Table 1), the temperature was varied systematically between higher values of about -3 and $-8^{\circ} \mathrm{C}$ to investigate the influence of temperature. For these samples, the temperature was recorded during the whole experiment with a sensor (iButton device) in the sealing cap of the sample holder. All samples were kept undisturbed in the $\mu \mathrm{CT}$ during the whole experiment which took 1 or 2 days. In one case, the measurement was extended to an entire week. $\mu \mathrm{CT}$ scans of a fixed (cylindrical) subvolume in the middle of the sample with a total height of $6.3 \mathrm{~mm}$ were conducted automatically with a time-interval of $3 \mathrm{~h}$. The nominal resolution was $10 \mu \mathrm{m}$ voxel size and the energy $45 \mathrm{kV}$. One scan took about 2 hours. In total, 45 time series were measured, leading to more than $600 \mu \mathrm{CT}$ scans.

For the analysis, a cubic volume of $6.3 \mathrm{~mm}$ edge length was extracted for each measurement and segmented into a binary file of ice and air. From the resulting three-dimensional images, the ice fraction and the SSA was calculated - details in Schleef and Löwe (2013). In the following, the results are exclusively presented in terms of the the ice volume fraction $\phi_{\mathrm{i}}$, which is directly obtained from the $\mu \mathrm{CT}$. The volume fraction can be related to the snow density via $\rho=\phi_{\mathrm{i}} \rho_{\mathrm{i}}$ with the temperature dependent density of ice $\rho_{\mathrm{i}}=917-920 \mathrm{~kg} \mathrm{~m}^{-3}$ $\left(0\right.$ to $\left.-20^{\circ} \mathrm{C}\right)$ (Petrenko and Whitworth, 1999). For the SSA, we use the definition as surface area per ice volume, which is related to the surface area per ice mass $\left(\mathrm{SSA}_{\mathrm{m}}\right)$ by $\mathrm{SSA}=$ $\rho_{\text {ice }} \mathrm{SSA}_{\mathrm{m}}$.

Though we mainly focus on the ice volume fraction and the SSA for the analysis, we have additionally evaluated the Euler characteristic $\chi$ of the samples. The Euler characteristic provides information about the topology which has been proven useful to understand the evolution of the snow microstructure under forced compression in a microcompression device (Schleef et al., 2014b). The Euler characteristic $\chi=2-2 g$ is related to the interface genus $g$, which is an indicator for the connectivity of a structure (cf. e.g., Michelsen et al. (2003)). The Euler characteristic typically assumes negative values, corresponding to high positive values of the interface genus. The higher the genus, the lower $\chi$ and the higher the number of inter-particle contacts. We calculated the Euler characteristic from the integral geometric approach of Minkowski functionals outlined by Michelsen et al. (2003). In accordance to the calculation of the SSA as a surface area per ice volume, we normalized the Euler characteristic $\chi$ by the ice volume.

For the isothermal tomography measurements and their analysis, we refer to Schleef and Löwe (2013) for an elaborate description of the experimental details. 
Table 1. Overview of experiments. Set numbers (1-8) correspond to natural snow, while (9-14) are snowmaker snow grown in the lab. The sets 9 and 10 were already used in Schleef and Löwe (2013) and included here for comparison. For each set, the number of samples $N_{\mathrm{S}}$ and the total number of measurements $N_{\mathrm{m}}$ per sample in a time series are given, in addition to applied stresses $\sigma$ and used temperatures $T$. The initial values of ice fraction $\bar{\phi}_{\mathrm{i}, 0}$ and SSA $\overline{\mathrm{SSA}}_{0}$ are averages over all samples within the set. For all observed crystal habits, the classification number is given according to Kikuchi et al. (2013), including potentially broken parts (I3a) of them.

\begin{tabular}{llllllll}
\hline Set no. & $N_{\mathrm{s}}$ & $\begin{array}{l}N_{\mathrm{m}} \\
\text { ( }\end{array}$ & $\begin{array}{l}\mathrm{Pa} \\
{ }^{\circ} \mathrm{C}\end{array}$ & $\begin{array}{l}\bar{\phi}_{\text {ice, } 0} \\
\overline{\mathrm{SSA}}_{0} \\
\mathrm{~mm}^{-1}\end{array}$ & Class. no. \\
\hline 1 & 2 & 32 & 133,215 & -18 & 0.08 & 92 & P3a, P3b, R1c, H1a, I2a \\
2 & 5 & 76 & $0,133,215,318$ & -18 & 0.11 & 64 & P2b, P4c, P4d \\
3 & 7 & 90 & $0,133,215,318$ & -18 & 0.07 & 102 & P3a, R1c, I2a \\
4 & 4 & 43 & $0,133,215,318$ & -18 & 0.08 & 91 & P3b, R1c \\
5 & 2 & 68 & 0 & -13 & 0.11 & 77 & C3b, C3c, C4d, P3a, P3b, A1a \\
6 & 2 & 30 & 0 & -13 & 0.09 & 75 & P3b, P4e, P4f, A2a, R1c \\
7 & 2 & 24 & 0 & -13 & 0.08 & 92 & C4b, C4d, P2b, H1a, H1b \\
8 & 2 & 24 & 0 & -13 & 0.06 & 86 & P1a, P2a, P3a, P3b, P4e, P4g \\
9 & 7 & 111 & $0,133,215,318$ & -18 & 0.11 & 66 & Not analyzed \\
10 & 2 & 32 & 215 & -18 & 0.10 & 69 & Not analyzed \\
11 & 1 & 19 & 0 & -13 & 0.07 & 74 & P3b, P3c, P4c \\
12 & 2 & 23 & 0 & -13 & 0.07 & 75 & P3b, P3c \\
13 & 1 & 8 & 0 & -13 & 0.12 & 66 & C1a, C1b, C1c, I1a \\
14 & 6 & 48 & 0,133 & $-3,-8,-13$ & 0.08 & 74 & P3b, P3c \\
\hline
\end{tabular}

\section{Results}

\subsection{Overview}

The natural, new snow samples show large variations in the initial values of SSA and density. The snowmaker samples also varied in their initial characteristics and parameters due to different temperature settings of the machine (Schleef et al., 2014a). Overall, the initial ice volume fractions ranged from about 0.05 to 0.12 . The initial SSA values were in the range $62-105 \mathrm{~mm}^{-1}$, and the initial $\chi$ values were between $-2 \times 10^{5} \mathrm{~mm}^{-3}$ and $-12 \times 10^{5} \mathrm{~mm}^{-3}$. The averaged initial values of $\phi_{\mathrm{i}}$ and SSA of each new snow type are listed in Table 1. The initial values had an influence on the settling, yielding a faster densification for a lower initial $\phi_{\mathrm{i}}$ and a faster SSA decay for a higher initial SSA, but variations of other parameters like temperature and stress also led to a high variability.

As a starting point for our subsequent analysis, we show the entire data for the temporal evolution of the ice volume fraction and the SSA for all samples in Fig. 1 and Fig. 2, respectively. Despite the variability, some trends are immediately visible, e.g., an influence of the initial SSA on the subsequent decay. However, other trends which may be expected (e.g., a clear ordering of the densification rates according to the applied stress) are clearly absent. A more detailed analysis of the individual influences is necessary.

For one randomly selected sample of natural snow at $-13^{\circ} \mathrm{C}$, we extended the observation to a whole week. From the analysis, we obtained the evolution of $\phi_{\mathrm{i}}$ and SSA at high temporal resolution, as shown in Fig. 3. For the given example, no external stress was applied, but the volume frac-

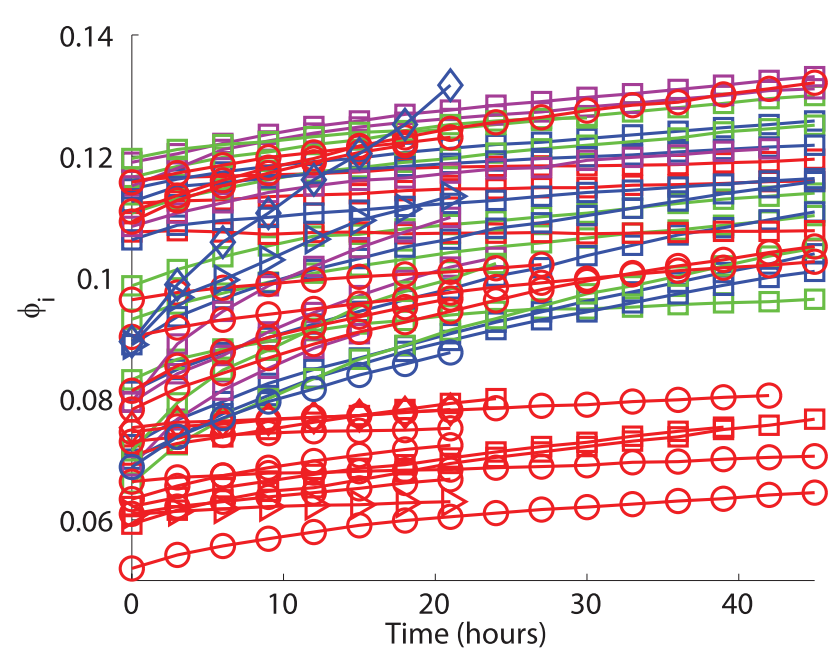

Figure 1. Evolution of the ice volume fraction $\phi_{\mathrm{i}}$ for all samples. Colors indicate different stress values: red $-0 \mathrm{~Pa}$; blue $-133 \mathrm{~Pa}$; green $-215 \mathrm{~Pa}$; magenta $-318 \mathrm{~Pa}$. Symbols indicated different temperatures: $\square-18{ }^{\circ} \mathrm{C}, \bigcirc-13{ }^{\circ} \mathrm{C}, \triangleright-8{ }^{\circ} \mathrm{C}, \diamond-3^{\circ} \mathrm{C}$ )

tion $\phi_{\mathrm{i}}$ increased by more than $40 \%$ from an initial value of about 0.11. At the same time, the SSA decreased from $77 \mathrm{~mm}^{-1}$ to $45 \mathrm{~mm}^{-1}$. A widely confirmed decay law for the SSA (Legagneux et al., 2004; Flanner and Zender, 2006; Kaempfer and Schneebeli, 2007; Schleef and Löwe, 2013) is given by

$\operatorname{SSA}(t)=\operatorname{SSA}(0)\left(\frac{\tau}{t+\tau}\right)^{1 / n}$ 


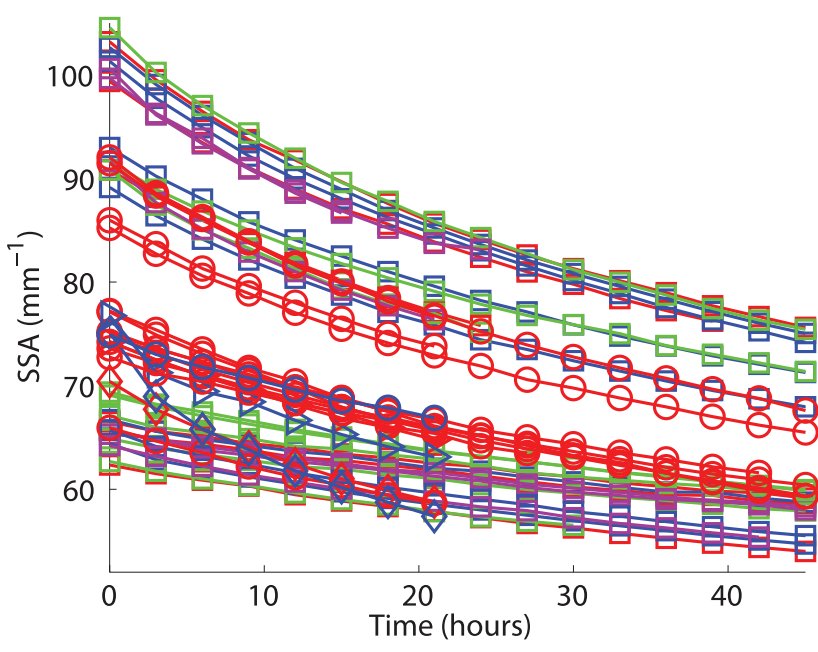

Figure 2. Evolution of the SSA for all samples. Colors indicate different stress values: red $-0 \mathrm{~Pa}$; blue $-133 \mathrm{~Pa}$; green $-215 \mathrm{~Pa}$; magenta $-318 \mathrm{~Pa}$. Symbols indicated different temperatures: $\square-$ $18^{\circ} \mathrm{C}, \bigcirc-13^{\circ} \mathrm{C}, \triangleright-8^{\circ} \mathrm{C}, \diamond-3^{\circ} \mathrm{C}$.

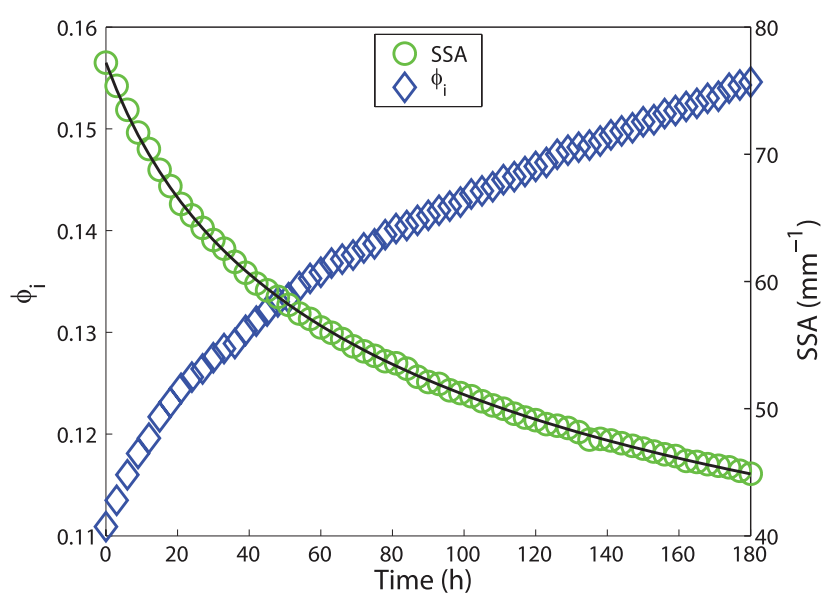

Figure 3. Evolution of ice volume fraction and SSA in 1 week at about $-13{ }^{\circ} \mathrm{C}$. The initial three-dimensional structure and crystal habit of this experiment are shown in Fig. 8 (bottom) and listed as snow 5 in Table 1. A fit of the SSA to Eq. (1) is plotted as black line.

with the parameters $\tau$ and $n$. A fit to the SSA data is shown in Fig. 3, with the parameters $\tau=27 \mathrm{~h}$ and $n=3.8\left(R^{2}>\right.$ 0.99 ).

For a visual demonstration of the microstructural evolution, we combined sections of the three-dimensional images (snow 5) to a time-lapse movie which is provided as supplementary material. The densification and coarsening is clearly visible in the movie and occurs in the absence of recognizable particle rearrangements and the creation of new interparticle contacts.

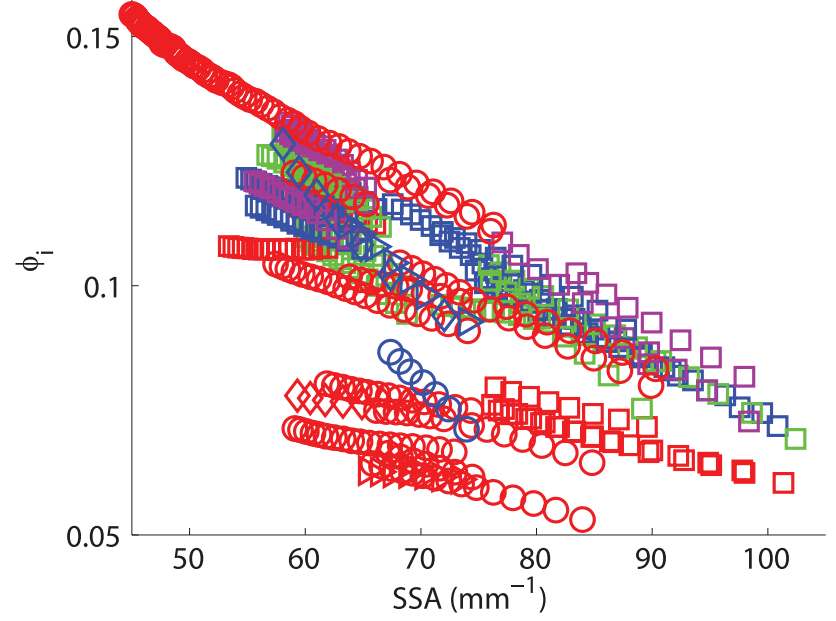

Figure 4. Plot of the ice volume fraction versus the SSA for all experiments reveals an almost linear relation for each time series. Legend: stress indicated by colors: red $-0 \mathrm{~Pa}$; blue $-133 \mathrm{~Pa}$; green $-215 \mathrm{~Pa}$; magenta $-318 \mathrm{~Pa}$. Temperature indicated by symbols: $\square-$ $18^{\circ} \mathrm{C}, \bigcirc-13^{\circ} \mathrm{C}, \triangleright-8^{\circ} \mathrm{C}, \diamond-3^{\circ} \mathrm{C}$;

\subsection{General relation between density and SSA}

Despite the common trends in the evolution of the SSA and the density, there is an apparent variability of individual curves shown in the previous section. However, the coupled evolution of both turns out to be governed by a generic feature. As suggested by Fig. 3, the increase of the volume fraction $\phi_{\mathrm{i}}$ seems to "mirror" the SSA decay. If the ice volume fraction $\phi_{\mathrm{i}}$ is plotted versus the SSA for all series (Fig. 4), an almost linear relation between both is consistently revealed, irrespective of the experimental conditions. Except for one sample, which showed no densification at all, all other series of measurements can be fitted to the empirical linear relation $\phi_{\mathrm{i}}=a \times \mathrm{SSA}+b$, with a coefficient of variation $R^{2}>0.94$. The fit parameters vary in the range $a=\left[-2 \times 10^{-3},-0.2 \times\right.$ $\left.10^{-3}\right]$ and $b=[0.08,0.26]$, depending on applied stresses, temperatures or crystal habits; not, however, in an apparent, systematic way, as shown in Fig. 4. We note that, likewise, a logarithmic law $\ln \left(\phi_{\mathrm{i}}\right)=a^{\prime} \times \mathrm{SSA}+b^{\prime}$ could be fitted to the data, with values $a^{\prime}=\left[-2 \times 10^{-2},-0.3 \times 10^{-2}\right]$ and $b^{\prime}=[-2.5,-0.4]$ and $R^{2}>0.93$. This logarithmic dependence was suggested by Legagneux et al. (2002) and Domine et al. (2007). The difficulty of discerning a logarithmic from a linear relation is not surprising, since $\ln (x) \approx-1+x$ for values $x$ close to 1 , where both models seem to be equally valid. A detailed analysis of the experimental parameters on the SSA evolution and the densification will be carried out below. 


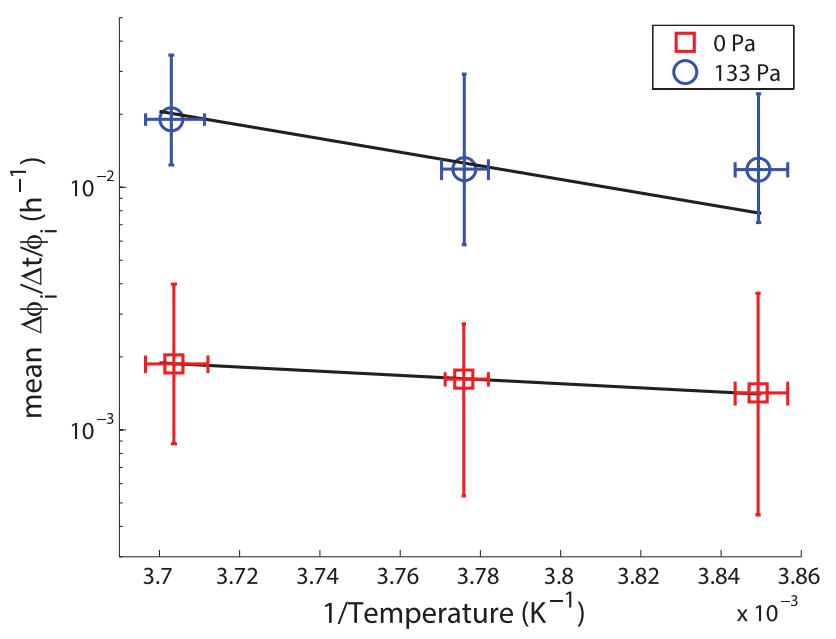

Figure 5. Densification rate averaged over $24 \mathrm{~h}$ as a function of temperature.

\subsection{Influence of temperature}

To investigate the influence of different (isothermal) temperatures, we measured the settling for one set of samples (snow 14 in Table 1) at three different laboratory temperatures. The temperature of the samples was recorded continuously during the experiments, resulting in mean values of $-3.1^{\circ} \mathrm{C},-8.3^{\circ} \mathrm{C}$ and $-13.4^{\circ} \mathrm{C}$. Even though additional fans were mounted inside the $\mu \mathrm{CT}$ to minimize temperature fluctuations, the temperature changed during each scan by up to $\pm 0.5^{\circ} \mathrm{C}$ due to the heating of the $\mathrm{X}$-ray tube. In addition, the defrosting cycles of the cold laboratory heat exchanger caused small changes in the temperature twice a day. In total, the temperature fluctuations were at a maximum of $\pm 0.6^{\circ} \mathrm{C}$ over 1 day, with the largest changes for the mean temperature at $-3.1{ }^{\circ} \mathrm{C}$. For each temperature, we conducted one series without a weight on the sample and another one with a weight corresponding to a stress of $133 \mathrm{~Pa}$, and we analyzed the density and the SSA.

\subsubsection{Densification rate}

The initial ice volume fractions of the samples were about 0.06-0.09. For the samples without applied stress, almost no densification was observed in 1 day. Therefore a clear dependency on the temperature could not be obtained from the data of these samples. In contrast, the series with an applied stress of $133 \mathrm{~Pa}$ showed a significant, steady densification of $27-48 \%$ per day, which is clearly influenced by the temperature. The temperature influence of the densification of snow is often described by an Arrhenius law (Bader, 1960; Arnaud et al., 2000; Kirchner et al., 2001; Delmas, 2013),

$\dot{\phi}_{\mathrm{i}} / \phi_{\mathrm{i}}=v \exp \left(-\frac{E}{k_{B} T_{K}}\right)$

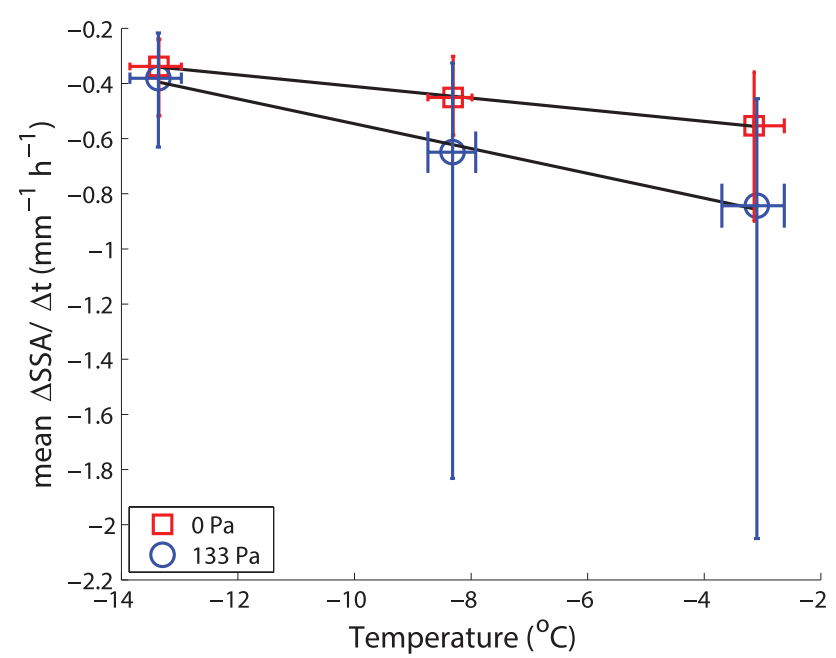

Figure 6. SSA decay rate averaged over $24 \mathrm{~h}$ as a function of temperature.

with a rate constant $v$, an activation energy $E$, the Boltzmann constant $k_{B}$ and the temperature $T_{K}$ in Kelvin. From the differences of the ice volume fraction between successive time steps, we obtain the experimental densification rates. Following the Arrhenius law, the mean densification rates per hour for each series are plotted against the inverse temperature in Kelvin in Fig. 5. The horizontal error bars result from the measured temperature fluctuations, whereas the vertical errors bars indicate the maximum deviations from the mean values. By fitting the results to Eq. (2), we find the parameters $v=4.8 \times 10^{8} \mathrm{~h}^{-1}$ and $E=0.56 \mathrm{eV}\left(R^{2}=0.49\right)$ for the experiments with a stress of $133 \mathrm{~Pa}$. The same fit for the experiments without stress yields $v=2.8 \mathrm{~h}^{-1}$ and $E=0.16 \mathrm{eV}$ $\left(R^{2}=0.99\right)$. However, there was only a marginal change in the density.

\subsubsection{SSA decrease rate}

The initial SSA of the samples ranged between 70 and $78 \mathrm{~mm}^{-1}$. For all samples, a steady decay of $12-31 \%$ in 1 day could be measured. Figure 6 shows the mean SSA decay per hour, with error bars calculated in the same way as described for the ice-fraction evolution. The SSA decay increased significantly with higher temperatures. At a temperature of about $-13{ }^{\circ} \mathrm{C}$, the decay was almost independent of the applied stress. In contrast, for higher temperatures, the experiments with a stress of $133 \mathrm{~Pa}$ showed an accelerated rate of SSA decay. The temperature influence can be best described with an empirical linear relation $\mathrm{S} \dot{S} \mathrm{~A}=\alpha T+\beta$, with the parameters $\alpha=-0.02$ and $\beta=-0.62\left(R^{2}>0.99\right)$ for the experiments with stress $\sigma=0$, and $\alpha=-0.04, \beta=$ $-0.99\left(R^{2}=0.99\right)$ for $\sigma=133 \mathrm{~Pa}$. This is valid if the temperature is given in ${ }^{\circ} \mathrm{C}$ and SSA in units $\mathrm{mm}^{-1} \mathrm{~h}^{-1}$. In Fig. 6, the experiments at higher temperatures and $\sigma=133 \mathrm{~Pa}$ have a disproportionate error on the SSA rate, which is caused by 


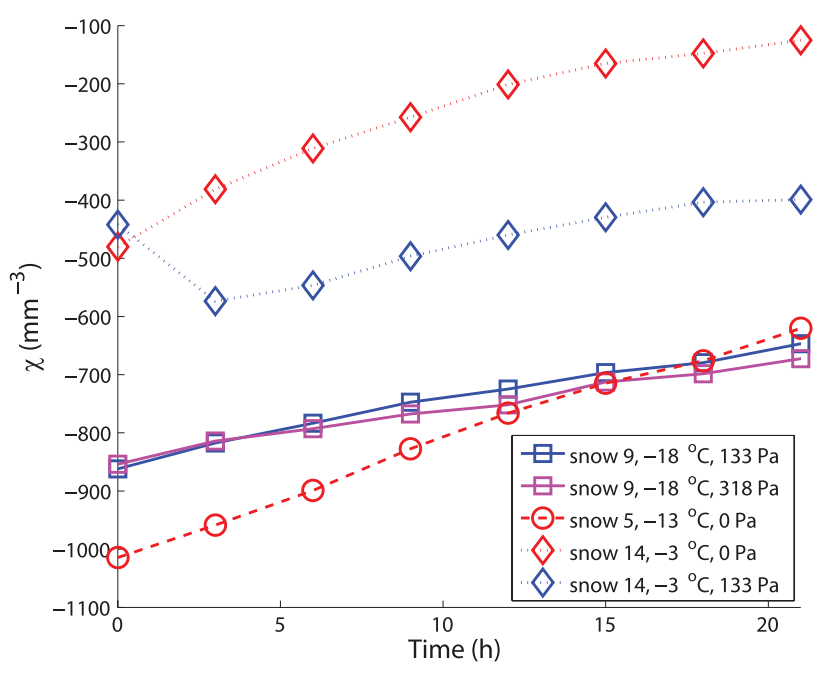

Figure 7. Selected examples of the evolution of the Euler characteristic $\chi$ for different new snow types (cf. Table 1) during the first day of settlement: The 1-week measurement (snow 5, Fig. 3), two examples of snow 9 with different applied stresses (taken from Schleef and Löwe (2013)), and two examples of snow 14 with different, applied stresses at $-3{ }^{\circ} \mathrm{C}$.

a much higher SSA difference between the first two measurements of the time series. By neglecting the first measurement, the difference of the SSA rate at high temperatures between the experiments with and without applied stress would only be small. The particularity of the first time step is revealed by the Euler characteristic, which is analyzed below.

\subsection{Influence of other morphological properties}

\subsubsection{Euler characteristic}

A few selected examples for the evolution of the Euler characteristic $\chi$ over 1 day are shown in Fig. 7. For most experiments, the Euler characteristic $\chi$ increases monotonically with a decreasing rate. In these cases, the rate increased slightly with increasing temperature, but an influence of external stress was not observed. This is shown for one example (snow 9 in Fig. 7). For some experiments, at higher temperatures, this monotonic behavior of the Euler characteristic disappears. The measurement without applied stress (snow 14, $-3^{\circ} \mathrm{C}, 0 \mathrm{~Pa}$ ) shows a monotonic increase, similar to the other experiments at lower temperatures, similar to the evolution of the 1-week measurement (snow 5) and similar to the experiments from Schleef and Löwe (2013) (snow 9). However, if the stress is changed to $133 \mathrm{~Pa}$ (snow 14 at $-3{ }^{\circ} \mathrm{C}, 133 \mathrm{~Pa}$ ), a different non-monotonic evolution of the Euler characteristic at the beginning of the experiment is observed. After this initial phase, the connectivity decreased again monotonically (i.e., increase of $\chi$ ), similar to the evolution of the corresponding experiment without applied stress. The rate was, however, slightly lower. Such a significant decrease of the Euler characteristic within the first 3 hours between the first and the second measurement has been observed only for a few measurements, predominantly at higher temperatures. This decrease of the Euler characteristic corresponds to an increase of the number of inter-particle contacts, which contributes to the decrease of the SSA (Schleef et al., 2014b). These cases gave rise to the larger error in the SSA rate for higher temperatures in Fig. 6.

\subsubsection{Crystal habit}

Finally, we turn to apparent visual differences in the morphology of the crystals. From the photographs, we compared the crystal habits of our samples to the classification of natural snow crystals (Kikuchi et al., 2013), as listed in Table 1. In most cases, we observed broken parts of the respective crystal types, which might be caused by sieving. However, also wind can lead to broken crystals in nature, and we could still identify the original crystal for the classification. An unambiguous classification for each snow sample was, however, not possible, because each sample contained a mixture of different habits. This was particularly the case for natural snow. For some samples, however, specific crystal habits dominated.

Figure 8 shows two examples of natural snow samples with a photo of the prominent crystal habit and the corresponding $\mu \mathrm{CT}$ image of the initial structure. The sample (Fig. 8, bottom) is the one with the evolution shown in Figure 3 (snow 5 in Table 1), with dominant crystal habit of skeletal columns with scrolls $(\mathrm{C} 3 \mathrm{c})$ and combinations of columns and bullets (A1a). For comparison, we picked another sample (Fig. 8, top) which had almost the same initial ice fraction (snow 2 in Table 1) but a different dominating crystal habit (broad branches, P2b). This sample was unique since no densification at all could be measured within 2 days at $-18^{\circ} \mathrm{C}$, in contrast to the previous sample (snow 5), which showed a densification of about $18 \%$ within the same span at $-13^{\circ} \mathrm{C}$. However, the large difference cannot be explained by the temperature, because, for all other samples, there is no trend for the densification between the measurements at -13 or $-18^{\circ} \mathrm{C}$. There are also other samples with smaller differences in the densification rates for the same volume fraction and the same temperature and stress. In contrast, for the SSA decay rate, no clear influence of the crystal habit has been found. In most cases, the SSA evolution at the same temperature is identical for the same SSA values.

\subsection{Combined influence of stress, temperature and morphology: parameterizations}

To provide an overall quantitative description of the SSA decrease rate and the densification rate, which accounts for all measured quantities, we set up a parameterization based on our observations and existing concepts from literature. 

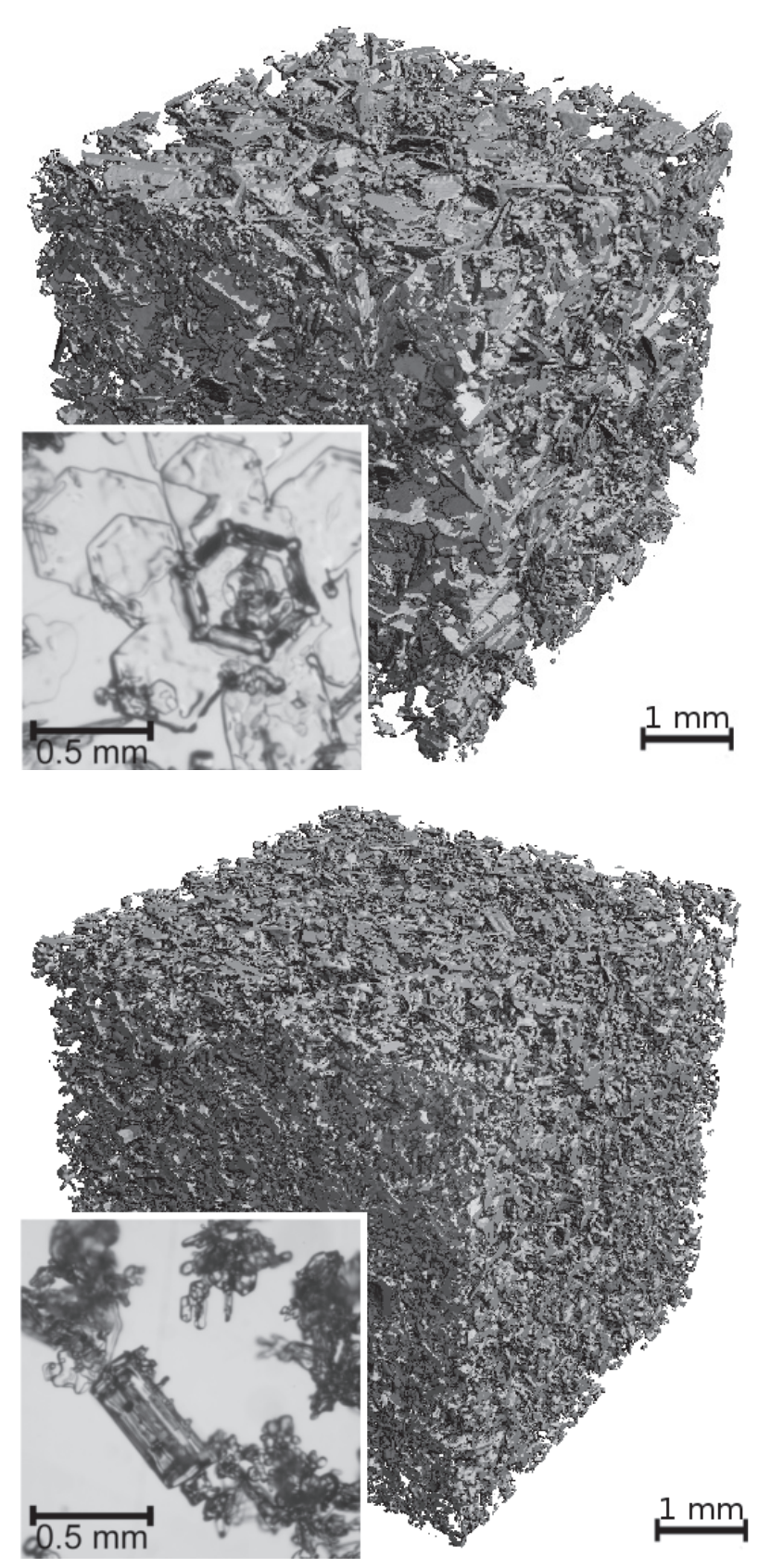

Figure 8. Examples of natural snow samples with a photograph of the crystal habit and an $\mu \mathrm{CT}$ image of the initial structure. The parameters of the sample at the top are $\phi_{\mathrm{i}, 0} \approx 0.1$ and $\mathrm{SSA}_{0} \approx$ $62 \mathrm{~mm}^{-1}$ (snow 2 in Table 1), and of the sample at the bottom $\phi_{\mathrm{i}, 0} \approx 0.1$ and $\mathrm{SSA}_{0} \approx 77 \mathrm{~mm}^{-1}$ (snow 5 in Table 1 , evolution shown in Fig. 3).

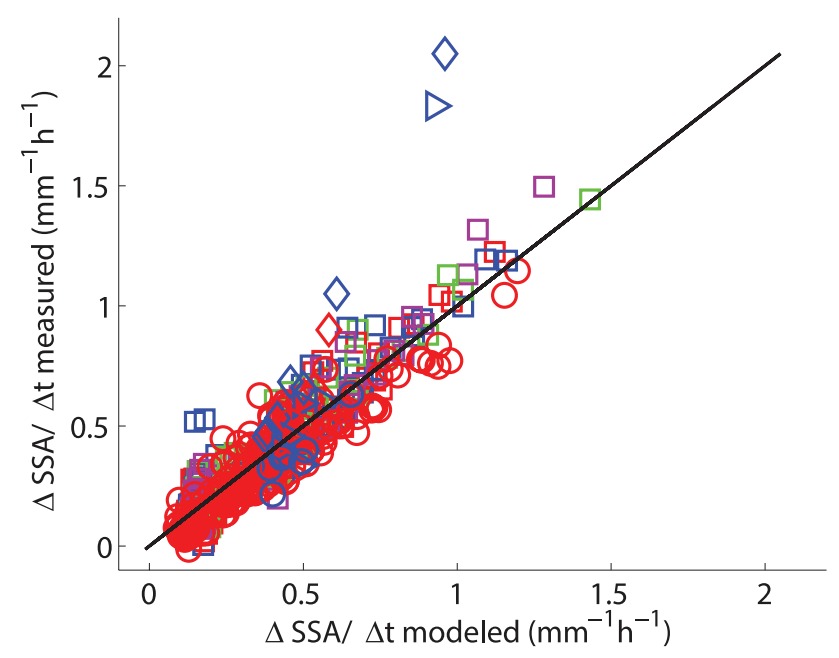

Figure 9. Scatterplot of SSA decay rates SSA, computed from Eq. (4) (horizontal axis) versus measurements. Different stresses are indicated by colors: red $0 \mathrm{~Pa}$, blue $133 \mathrm{~Pa}$, green $215 \mathrm{~Pa}$, magenta $318 \mathrm{~Pa}$; different temperatures are indicated by the symbols: $\square-18{ }^{\circ} \mathrm{C}, \bigcirc-13^{\circ} \mathrm{C}, \triangleright-8^{\circ} \mathrm{C}, \diamond-3^{\circ} \mathrm{C}$; snow types are indistinguishable.

\subsubsection{SSA decrease rate}

For the SSA decrease, we start from the widely used power law given in Eq. (1). This is motivated by the very good agreement of Eq. (1) for the 1-week measurement (Fig. 3), even though other functional forms are also discussed in literature (Taillandier et al., 2007). To proceed, we note that Eq. (1) is the solution of the differential rate equation

$\mathrm{SS} A=A \times \mathrm{SSA}^{m}$,

if the parameters from Eq. (1) are chosen according to $n=$ $m-1$ and $\tau=-\frac{1}{A n} \operatorname{SSA}(0)^{-n}$. The proportionality of $\tau$ to $\operatorname{SSA}(0)^{-n}$ is in accordance with the derivation from Legagneux et al. (2004). On the other hand, our observations from Sect. 3.3 indicate a linear influence of the temperature on the SSA decrease rate. However, no influence on the applied stress has been observed during coarsening, except for one case discussed in Sect. 3.3.2. In addition, we have observed that, for some cases, the initial SSA rates are influenced by topological changes during densification (Fig. 7), as described by the Euler characteristic $\chi$ (Sect. 3.4.1). In summary, we chose the following form for the statistical model

$\mathrm{SS} A=(a+b T) \mathrm{SSA}^{m}+c \dot{\chi}$,

with the parameters $a, b, c$ and $m$. Incorporating the topological influence $\dot{\chi}$ in an additive way in Eq. (4) is thereby in accordance to the relation found by compression experiments (Schleef et al., 2014b). Thereby, we consider that the SSA is not only affected by metamorphism but also by the number of 


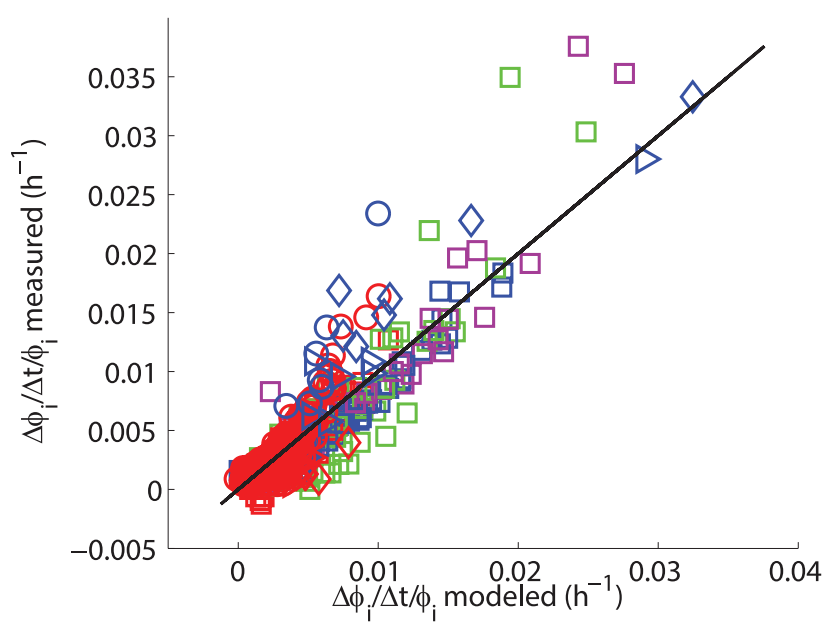

Figure 10. Scatterplot of densification rates $\dot{\phi} / \phi$, computed from Eq. (7) (horizontal axis) versus measurements (vertical axis). Different stresses are indicated by colors: red $-0 \mathrm{~Pa}$; blue $-133 \mathrm{~Pa}$; green $-215 \mathrm{~Pa}$; magenta $-318 \mathrm{~Pa}$. Different temperatures are indicated by symbols: $\square-18^{\circ} \mathrm{C}, \bigcirc-13^{\circ} \mathrm{C}, \triangleright-8^{\circ} \mathrm{C}, \diamond-3^{\circ} \mathrm{C}$; snow types are indistinguishable.

contacts during settling between the ice grains. Crucial topological changes, i.e., the creation of new contacts within the structure, occurred only for a few samples at the beginning of the series of measurements.

A fit of Eq. (4) to the SSA rates obtained from the difference $\Delta \mathrm{SSA} / \Delta t$ of successive measurement typically within 3 hours for our complete data set yield $a=2.9 \times 10^{-7}, b=$ $9.5 \times 10^{-9}, c=-3.5 \times 10^{-3}$ and $m=3.5$ with $R^{2}=0.83$ $\left(T\right.$ in ${ }^{\circ} \mathrm{C}$, SSA in $\mathrm{mm}^{-1}$ and $\dot{\chi}$ in $\mathrm{mm}^{-3}$ ). The scatterplot between modeled and measured SSA rates is shown in Fig. 9.

If we neglect the measurements where noticeable topological changes $(\dot{\chi}<0)$ occurred, which was only the case for 10 samples for the first measurements, we could simplify the model to

$\mathrm{SS} \mathrm{A}=\left(a^{\prime}+b^{\prime} T\right) \mathrm{SSA}^{m^{\prime}}$,

leading to fit parameters $a^{\prime}=1.1 \times 10^{-6}, b^{\prime}=3.1 \times 10^{-8}$ and $m^{\prime}=3.1$. In this case, we obtain an even improved performance $\left(R^{2}=0.87\right)$. This is particularly interesting, given the practical impossibility to measure the Euler characteristic without tomography.

\subsubsection{Densification rate}

A parameterization for the densification rate $\dot{\phi}_{\mathrm{i}}$ for all mea-

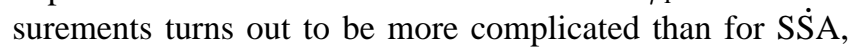
since $\dot{\phi}_{\mathrm{i}}$ is not only influenced by temperature and the initial value $\phi_{\mathrm{i}, 0}$, but also by the stress and the crystal habit, as described before.

To motivate a model which aims to fit the entire data, we start from the common stress dependence of the strain rate for visco-plastic flow of polycrystalline ice, which is

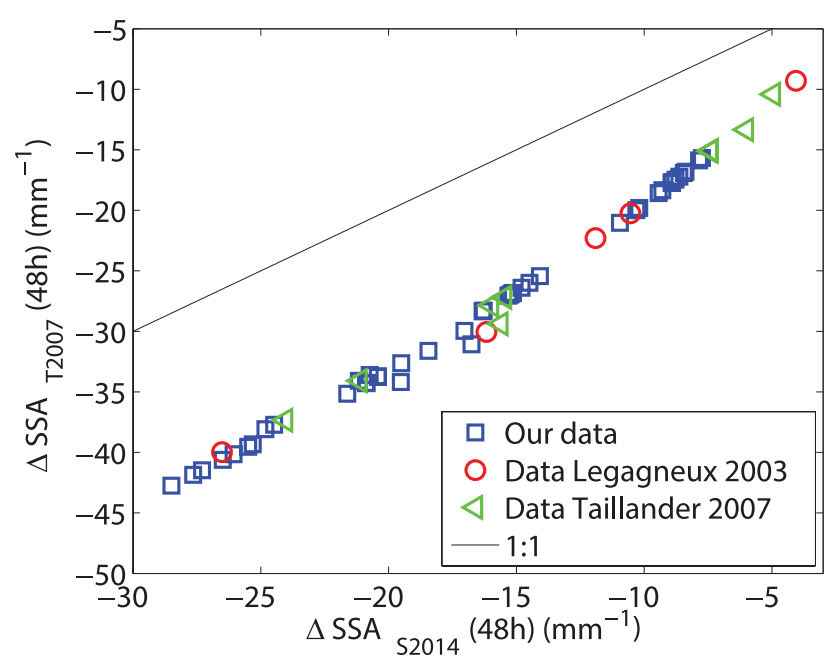

Figure 11. Scatterplot of the predicted SSA difference $\triangle \mathrm{SSA}(48 \mathrm{~h})$ after $48 \mathrm{~h}$, obtained from the parameterizations Eq. (13) in Taillandier et al. (2007) (vertical axis) and from the present parameterization, Eq. (5) (horizontal axis), which were respectively applied to the different available data sets (legend).

commonly described by Glen's law for secondary creep, $\dot{\varepsilon}=A \sigma^{k}$ (Petrenko and Whitworth, 1999). A similar form is believed to be valid for snow (Kirchner et al., 2001). In a one-dimensional system, the strain rate $\dot{\varepsilon}$ can be taken as the relative densification rate $\dot{\varepsilon}=\dot{\phi}_{\mathrm{i}} / \phi_{\mathrm{i}}$ (cf. also Schleef and Löwe (2013)), leading to

$\dot{\phi}_{\mathrm{i}} / \phi_{\mathrm{i}}=A \sigma^{k}$,

with a constant $A$ containing the rate of the process.

On the other hand, we have empirically observed that the volume fraction is almost linearly related to the SSA (Sect. 3.2). Hence, we chose the rate in Eq. (6) to be determined mainly by the SSA rate, $A=B$ SSA, and end up with

$\dot{\phi}_{\mathrm{i}} / \phi_{\mathrm{i}}=B \mathrm{~S} \dot{\mathrm{SA}} \sigma^{k}$

for our parameterization model, which includes two parameters, $B$ and $k$. We note that integrating Eq. (7) in fact implies $\ln \left(\phi_{\mathrm{i}}\right) \sim$ SSA and not a linear dependence. This is, however, in accordance with the result from Sect. 3.2, in which the logarithmic or the linear relation are indistinguishable. Thus, Eq. (7) constitutes a reasonable trade off and naturally includes a dependence of the densification rate on the density itself.

A fit of Eq. (7) to the densification rates $\Delta \phi_{\mathrm{i}} / \Delta t$ obtained from successive measurements typically within 3 hours for our complete data set yields $B=-6.6 \times 10^{-3}$ and $k=0.18$

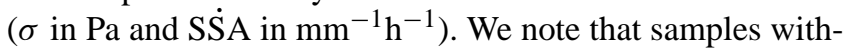
out a weight are assigned a remaining, non-zero stress of $5 \mathrm{~Pa}$, caused by the small but non-negligible overburden of the overlying snow inside the $\mu \mathrm{CT}$ sample holder on top of 
the evaluation cube. The same value was chosen by Schleef and Löwe (2013). The scatterplot between modeled and measured densification rates is shown in Fig. 10, yielding $R^{2}=$ 0.82 .

As suggested by the results from Schleef et al. (2014b), the Euler characteristic has an influence on the densification by discerning different connectivities. Accordingly, a slight improvement of the parameterization (7) is obtained by including the Euler characteristic via

$\dot{\phi}_{\mathrm{i}} / \phi_{\mathrm{i}}=\left(B^{\prime} \sigma^{k}+C^{\prime} \dot{\chi}\right) \mathrm{S} \dot{\mathrm{SA}}$

which yields $R^{2}=0.85$. In contrast to Eq. (4), where the additive dependence of the SSA decrease on the Euler characteristic was motivated by process insight (Schleef et al., 2014b), the inclusion of $\chi$ in Eq. (8) is purely empirical.

\subsection{Comparison to an existing parameterization}

Finally, we compare our parameterization (5) for the SSA evolution to an existing parameterization from Taillandier et al. (2007), who derived a parameterization $\operatorname{SSA}_{\mathrm{T} 2007}(t, T, \operatorname{SSA}(0))$ - Eq. (13) in their paper - for the isothermal and quasi-isothermal evolution of the SSA, with time $(t)$ for given temperature $(T)$ and initial value SSA(0). The parameterization was derived from SSA measurements which were conducted by the BrunauerEmmett-Teller (BET) method of gas adsorption, with new-snow samples collected after snowfall. With respect to the involved parameters, this is exactly equivalent to our parameterization $\operatorname{SSA}_{\mathrm{S} 2014}(t, T, \operatorname{SSA}(0))$, which is obtained from integrating Eq. (5). To compare the overall trends of both parameterizations, we have computed the SSA difference after $48 \mathrm{~h}$, viz. $\triangle \operatorname{SSA}_{X}(48 h)=$ $\operatorname{SSA}_{X}(48 \mathrm{~h}, T, \operatorname{SSA}(0))-\operatorname{SSA}_{X}(0 \mathrm{~h}, T, \operatorname{SSA}(0))$ for both formulations $X=\mathrm{T} 2007, \mathrm{~S} 2014$, as a measure of the averaged SSA decay rate on the first day after snowfall. To use realistic values for $(T, \operatorname{SSA}(0))$ from real data sets, we have evaluated the difference $\Delta \mathrm{SSA}_{X}(48 \mathrm{~h})$ for the present data set 45 tuples of $(T, \operatorname{SSA}(0))$-, the isothermal experiments 1-9 from Taillandier et al. (2007) (9 tuples), and the experiments 1-5 from Legagneux et al. (2003) (5 tuples). The results are shown in Fig. 11. A clear deviation from the 1:1 line is observed. In general, our parameterization of the SSA decay rate is biased low, compared to Taillandier et al. (2007). This bias remains, even if $\Delta \operatorname{SSA}_{X}(t)$ is evaluated for other $t \mathrm{~s}$. However, the parameterization T2007, based on BET measurements, and the parameterization S2014, based on $\mu \mathrm{CT}$ measurements, are clearly correlated. In both cases, the major influence on the SSA decrease rate stems from the initial value $\operatorname{SSA}(0)$.

\section{Discussion}

\subsection{Main result}

We start the discussion with the parameterization of the SSA and the densification for new snow under isothermal conditions (Sect. 3.5). The parameterizations are motivated by available models for the SSA (Legagneux et al., 2004) and Glen's law for creep of polycrystalline ice (Petrenko and Whitworth, 1999). Conceptually, current snowpack models (Vionnet et al., 2012; Jordan, 1991; Bartelt and Lehning, 2002) use a similar approach for the densification, but still based on traditional grain size to characterize the microstructure. Only recently was the model Crocus reformulated (Carmagnola et al., 2014) to use SSA as the simplest objective, morphological metric directly.

Our experiments focused only on new snow with low density and high SSA, and most of our results are probably not valid for denser snow. In contrast to denser snow under isothermal metamorphism, we found that the densification rate is directly related to metamorphism via the SSA decrease rate. This is reflected by the consistent linear variation of the ice volume fraction with the SSA (Fig. 4). This observation was implemented in the parameterization by a prefactor in the densification rate, which is proportional to the SSA rate. We have set up the parameterization for the densification in a way to guarantee that both evolution laws are only dependent on the quantities $\phi_{\mathrm{i}}$ (or the density), the stress $\sigma$, the SSA and the $T$ to best fit the entire available data of new snow. These quantities are directly available in snowpack models, and Eqs. $(5,7)$ provide a closed set of empirical, microstructural evolution equations for the density and the SSA under isothermal conditions. Both microstructural parameters, SSA and density can also be obtained in the field without the use of tomography (Matzl and Schneebeli, 2006; Gallet et al., 2009; Arnaud et al., 2011).

\subsection{Comparison with an existing parameterization}

Our comparison with the parameterization from Taillandier et al. (2007) (Sect. 3.6) has revealed that our parameterization Eq. (4) always underestimates the average SSA decay in $48 \mathrm{~h}$ for the given temperature and initial SSA when compared to their result (Fig. 11). Different explanations for these deviations are possible. First, both parameterizations are based on different time scales. Our measurements focus only on the evolution of the SSA typically within 2 days at a high temporal resolution of $3 \mathrm{~h}$. In contrast, Taillandier et al. (2007) focuses on the evolution of the SSA over seasonal time scales from 1 to 100 days. Since their first measurement was conducted only after $24 \mathrm{~h}$, the parameterization in Taillandier et al. (2007) might lack accuracy in this initial stage. Thus, for practical purposes, a combination of both parameterizations might be envisaged to cover all time periods. Second, differences in the magnitude of temperature fluctuations 
might have an influence. If the isothermal experiments from Taillandier et al. (2007) were subject to temperature fluctuations larger than our accuracy of $\pm 0.6^{\circ} \mathrm{C}$, these fluctuations might cause an increase of the SSA decay rate, according to mechanisms mentioned in Pinzer and Schneebeli (2009). A quantitative estimate of this effect is, however, not yet possible. Third, a systematic error of the $\mu \mathrm{CT}$ measurements compared to BET measurements used in Taillandier et al. (2007) at these very high SSA values could not be ruled out. The comparison of BET and $\mu \mathrm{CT}$ from Kerbrat et al. (2008) has not revealed a systematic bias, though, but the uncertainty between both methods clearly increases at high SSA values. For very high SSA values, our $\mu \mathrm{CT}$ measurements with a voxel size of $10 \mu \mathrm{m}$ are at the limit of the resolution. Ideally, remaining uncertainties about absolute values of very high SSA should be further investigated within dedicated intercomparison experiments.

The origin of the remaining differences between both parameterizations could not be convincingly explained. However, the trends from Fig. 11 obtained from the two parameterizations, which were based on different experimental techniques ( $\mu \mathrm{CT}$ vs BET), are highly consistent. This motivates to measure the SSA of new snow also by other, less demanding techniques in the field. This will help to explore the influence of the initial SSA on new snow densification and improve the performance of snowpack models. Below, we discuss the particularities of the SSA decrease rate and densification rate in view of the involved parameters.

\subsection{SSA decrease rate}

Our simple parameterization for the SSA change (4) yielded good agreement for almost all of our measurement data. The exponent $m$, obtained from the fit, must be compared to $n$ from the widely used Eq. (1) via $n=m-1$, yielding $n=2.5$. As already outlined by Schleef and Löwe (2013), the precise value of $n$ is difficult to estimate if the duration of the experiment is similar to $\tau$, which is typically on the order of 1 day. This is confirmed by the 1-week measurement which allowed a better estimate of the fit parameters in Eq. (1). The obtained exponent $n=3.8$ agreed well with the results of Legagneux et al. (2004), who found $n=3.4-5.0$ at a temperature of $-15^{\circ} \mathrm{C}$. In contrast, the results of the short time measurements did not lead to a conclusive estimate for $n$. Also, the fits to the 2-day time series by Schleef and Löwe (2013) gave higher values of $n$ and only an adapted combination of all series resulted in a similar $n$ of about 3.9. However, the value $n=2.5$ indicates that, even for short times, the SSA decrease rate is dominantly influenced by the present value of the SSA in a non-linear way. It is generally believed that the value of $n$ is also influenced by temperature, potentially caused by different underlying mechanisms of mass transport (Vetter et al., 2010; Löwe et al., 2011). In view of the difficulties of estimating $n$ for the short time series, we have restricted ourselves to an inclusion of the temperature dependence into the prefactor in Eq. (4) to account for the acceleration of metamorphism at higher temperatures (Fig. 6).

We have previously observed that the SSA evolution was in fact independent of the densification or the applied stress, respectively (Schleef and Löwe, 2013). This was confirmed here for all experiments conducted at lower temperatures of $-13^{\circ} \mathrm{C}$ or $-18^{\circ} \mathrm{C}$ (cf. Table 1 ). This behavior seems to be generally valid for all examined types of new snow. In addition, no difference could be observed between the evolution of sieved, natural, new snow and snowmaker snow, which is in agreement with the results presented by Schleef et al. (2014a). The reason for the negligible stress dependence at low temperatures is that coarsening is the only relevant process. In these cases, the Euler characteristic is a monotonic function with time (this is further explained below). At higher temperatures, we have also observed cases in which the Euler characteristic initially decreased. This is a clear indicator of structural rearrangements and newly formed iceice contacts, which contribute to the SSA decrease (Schleef et al., 2014b). This was, however, observed only for a few cases. If present, the structural rearrangements and their impact on the SSA do depend on stress. This was revealed by the 2 (out of 584) $\Delta \mathrm{SSA} / \Delta t$ outliers in Fig. 9. These are the first values of the series of measurements with an applied stress of $133 \mathrm{~Pa}$ at temperatures of $-3^{\circ} \mathrm{C}$ and $-8^{\circ} \mathrm{C}$. For these exact measurements, a significant, direct influence of the applied stress on the SSA evolution was observed, which is not captured by the model (4). The data are, however, too limited to investigate this effect in greater detail. Apart from that, the parameterization in Eq. (4), which is solely based on common snowpack model parameters, is well suited for modeling the SSA decrease of new snow.

\subsection{Densification rate}

The analysis of $\dot{\phi}_{\mathrm{i}}$ is based on the observation of the almost linear relation between the evolution of $\phi_{\mathrm{i}}$ and SSA for each series of measurement (Fig. 4). Measurements of Legagneux et al. (2002); Domine et al. (2007) show a logarithmic relation between density and SSA, which is, however, derived from independent measurements in a seasonal snowpack and covers much wider SSA and density ranges. As outlined in Sect. 3.2, a logarithmic relation for each of our series of measurements would also be possible here, and the linear relation might only be an approximation for short observation times. It is, however, not the functional form which is worth mentioning, but rather the fact that the density evolution and the SSA evolution are intimately related.

In contrast to the SSA rate, a direct temperature dependence of the densification rate is less pronounced in the overall behavior. This stems from the fact that the main impact of densification comes from metamorphism itself via the SSA rate in Eq. (7), which implicitly contains a temperature dependence as discussed in the previous section. In general, one may also expect an explicit temperature dependence for the 
creep rate $A$ in Eq. (7). The Arrhenius analysis of the temperature dependence for one of the sets for two stress values (Fig. 5) revealed that the densification is almost negligible for the case without weight. For the experiments with applied stress, a faster rate of $\dot{\phi}_{i} / \phi_{i}$ could only be observed at about $-3{ }^{\circ} \mathrm{C}$. The Arrhenius fit (2) yields an activation energy in the same order of magnitude as known for different possible processes in ice (about $1 \mathrm{eV}$, cf. Kirchner et al. (2001) and references therein), but the limited amount of data with just one series of measurement at $-3^{\circ} \mathrm{C}$ and $133 \mathrm{~Pa}$ did not allow for conclusive parameter estimates. Obtaining reliable data for higher temperatures by desktop tomography is generally difficult, since the time scales for the fast structural changes in new snow are already on the order of the scanning times; image artifacts arise. Due to this technical limitation, most experiments were conducted at $-13^{\circ} \mathrm{C}$ or $-18^{\circ} \mathrm{C}$, where no general trend for a faster densification at higher temperatures could be observed.

\subsection{The influence of other morphological parameters}

Besides the most important microstructural parameters, density and SSA, we have also classified crystal habits to make contact to traditional characterization of crystal morphology and calculated the Euler characteristic to make contact with more advanced morphological metrics.

\subsubsection{Crystal habit}

For selected examples, the classification of crystal habits has helped to empirically interpret experimental scatter. The examples in Fig. 8 have shown that densification can easily differ by about $18 \%$, which cannot be explained by the temperature difference alone. Differences in crystal habit and their influence on the densification rate are not captured by our parameterization, which contains the SSA as the only morphological parameter. It seems unlikely that SSA is a sufficient morphological description of new snow type in the densification rate, as suggested by Eq. (7). However, for most of our measurements, the parameterization in Eq. (7) works reasonably well, even though only two fit parameters are involved. In contrast, for the SSA evolution, the crystal habit does not have an evident influence. Similar decay rates were found for samples with similar initial SSA but different crystal habits. Overall, the classification in terms of crystal habits was only of limited use. Some influence of the habit might be acknowledged, but future effort should rather aim at other quantitative, morphological parameters to explain the remaining scatter.

\subsubsection{Euler characteristic}

As suggested by recent compression experiments of new snow (Schleef et al., 2014b), the Euler characteristic might be a candidate morphological parameter to better interpret the evolution of SSA and density. Quantitatively, we have seen that the inclusion of the Euler characteristic in the parameterizations with Eqs. (4) and (8) only makes a slight difference for the very initial stage at which some particle rearrangements are noticeable. For the majority of samples, we observed a monotonic increase of the Euler characteristic, or, equivalently, a monotonic decrease of the number of contacts. This is expected as a consequence of coarsening of bicontinuous morphologies alone (Kwon et al., 2007), where contacts, made of fine filaments, disappear. For a highly porous material like new snow, the slow creep deformation considered here does not cause significant structural rearrangements and new contacts. This is also confirmed by visual inspection of the deformation in the movie (cf. supplementary material). For a few experiments, the Euler characteristic signaled an increase of the connectivity at the beginning. This was the case for samples with faster creep rates due to higher temperature, higher stresses or a very tenuous structures. In these cases, an influence on the evolution of SSA and $\phi_{\mathrm{i}}$ can be observed, which is not captured by Eqs. (4) and (8). However, initial structural rearrangements stabilize quickly. This is consistent with externally forced rearrangements in deformation controlled compression experiments (Schleef et al., 2014b), though in a less pronounced way.

Overall, the inclusion of the Euler characteristic as additional morphological parameter does not seem to be crucial for isothermal densification and metamorphism of new snow, at least for lower temperatures. However, the Euler characteristic has clearly helped to identify situations in which the evolution was not only governed by coarsening alone. In common snowpack models, additional morphological information beyond SSA is empirically included in the dendricity parameter (Vionnet et al., 2012; Lehning et al., 2002). This parameter is actually not sufficiently exploited yet, since new snow is always assigned the same dendricity, irrespective of the actual morphology of the crystals. The inclusion of an additional, objective parameter seems crucial, if the remaining scatter in SSA decrease rate and densification rate is an issue. To improve the understanding of new snow densification beyond Eq. (7), it seems important to also replace the dendricity by an objective microstructural parameter which captures relevant differences in crystal morphology. A candidate might be the anisotropy parameter $Q$, as pursued by Löwe et al. (2013); Calonne et al. (2014) to reduce the scatter in the data for the thermal conductivity. A direct application of the methods from Löwe et al. (2013) is, however, not possible, since the correlation function for new snow can certainly not be approximated by a simple exponential form. A potential generalization of the methods from Löwe et al. (2013), tailored to the evolution of new snow, will be addressed in future work. 


\section{Conclusions}

We have compiled a large data set of 45 time series (and a total of $600 \mu \mathrm{CT}$ measurements) of in situ experiments of new snow densification and metamorphism by $\mu \mathrm{CT}$. For a quantitative characterization of all experiments, we have derived a parameterization for the SSA decrease and densification rate, which performs reasonably well $\left(R^{2}=0.87,0.82\right.$, respectively) for the entire data set of new snow experiments which were evaluated for the present analysis. The parameterization is only based on the parameters SSA, density, temperature and stress, which are already available in current snowpack models, and which can be easily measured in the field. With these parameters, the main influences of metamorphism and densification of new snow can be quantitatively described. Advanced morphological metrics like the Euler characteristic give additional insight in the interpretation of the SSA and density evolution. The parameterizations have, however, not improved significantly upon inclusion of this parameter. This might be different for high temperatures close to $0^{\circ} \mathrm{C}$, where only few data are available due to the experimental limitations of $\mu \mathrm{CT}$ imaging for fast microstructural changes. It is, however, likely that an additional morphological parameter besides the SSA is required to reduce the remaining scatter in the description of new-snow densification. This will require additional, theoretical work to guide the choice of a relevant parameter and suggest functional forms for parameterizations which improve existing ones.

The comparison of our parameterization for the SSA (as a function of time, temperature and initial SSA) with a formally equivalent one from Taillandier et al. (2007) has revealed a bias in the absolute values of SSA decrease. The trends of both formulations are, however, highly consistent. These trends can probably also be reproduced by simpler SSA retrieval methods (other than $\mu \mathrm{CT}$ or BET) which are more convenient to use in the field. This is important for further validation of snowpack models. We have shown that the rate of SSA decrease, and thereby the SSA itself, probably has the most dominant influence on isothermal densification of new snow. Hence, monitoring the SSA for operational purposes might greatly help to constrain the initial densification of snow after snowfall.

\section{The Supplement related to this article is available online at doi:10.5194/tc-8-1825-2014-supplement.}

Acknowledgements. We thank Florent Domine and two anonymous reviewers for their helpful suggestions on the manuscript. This work was funded by the Swiss National Science Foundation (SNSF) through grant no. 200021132549.

Edited by: F. Domine

\section{References}

Arnaud, L., Barnola, J. M., and Duval, P.: Physical modeling of the densification of snow / firn and ice upper part of polar ice sheets, in: Physics of Ice Core Records, edited by Hondoh, T., vol. 159, pp. 285-305, Hokkaido University Press, Sapporo, Japan, 2000.

Arnaud, L., Picard, G., Champollion, N., Domine, F., Gallet, J., Lefebvre, E., Fily, M., and Barnola, J.: Measurement of vertical profiles of snow specific surface area with a $1 \mathrm{~cm}$ resolution using infrared reflectance: instrument description and validation, J. Glaciol., 57, 17-29, 2011.

Bader, H.: Theory of densification of dry snow on high polar glaciers, US Army SIPRE Res. Rep., 69, 1960.

Bartelt, P. and Lehning, M.: A physical SNOWPACK model for the Swiss avalanche warning Part I: numerical model, Cold Reg. Sci. Technol., 35, 123-145, 2002.

Cabanes, A., Legagneux, L., and Domine, F.: Evolution of the specific surface area and of crystal morphology of Arctic fresh snow during the ALERT 2000 campaign, Atmos. Environ., 36, 27672777, 2002.

Cabanes, A., Legagneux, L., and Domine, F.: Rate of evolution of the specific surface area of surface snow layers, Environ. Sci. Technol., 37, 661-666, 2003.

Calonne, N., Flin, F., Geindreau, C., Lesaffre, B., and Rolland du Roscoat, S.: Study of a temperature gradient metamorphism of snow from 3-D images: time evolution of microstructures, physical properties and their associated anisotropy, Cryosphere Discuss., 8, 1407-1451, 2014

Carmagnola, C. M., Morin, S., Lafaysse, M., Domine, F., Lesaffre, B., Lejeune, Y., Picard, G., and Arnaud, L.: Implementation and evaluation of prognostic representations of the optical diameter of snow in the SURFEX/ISBA-Crocus detailed snowpack model, The Cryosphere, 8, 417-437, 2014 . http://www.the-cryosphere-discuss.net/8/417/2014/.

Delmas, L.: Influence of snow type and temperature on snow viscosity, J. Glaciol., 59, 87-92, 2013.

Domine, F., Taillandier, A.-S., and Simpson, W. R.: A parameterization of the specific surface area of seasonal snow for field use and for models of snowpack evolution, J. Geophys. Res., 112, F02031, 2007

Flanner, M. G. and Zender, C. S.: Linking snowpack microphysics and albedo evolution, J. Geophys. Res., 111, D12208, 2006.

Gallet, J.-C., Domine, F., Zender, C. S., and Picard, G.: Measurement of the specific surface area of snow using infrared reflectance in an integrating sphere at 1310 and $1550 \mathrm{~nm}$, The Cryosphere, 3, 167-182, 2009, http://www.the-cryosphere-discuss.net/3/167/2009/.

Jordan, R.: A one-dimensional temperature model for a snow cover: Technical documentation for SNTHERM.89, CRREL Spec. Rep., 91-16, 1991.

Kaempfer, T. and Schneebeli, M.: Observation of isothermal metamorphism of new snow and interpretation as a sintering process, J. Geophys. Res., 112, D24101, 2007.

Kerbrat, M., Pinzer, B., Huthwelker, T., Gaeggeler, H., Ammann, M., and Schneebeli, M.: Measuring the specific surface area of snow with X-ray tomography and gas adsorption: comparison and implications for surface smoothness, Atmos. Chem. Phys., 8, 1261-1275, 2008, http://www.atmos-chem-phys.net/8/1261/2008/. 
Kikuchi, K., Kameda, T., Higuchi, K., and Yamashita, A.: A global classification of snow crystals, ice crystals, and solid precipitation based on observations from middle latitudes to polar regions, Atmos. Res., 132-133, 460-472, 2013.

Kirchner, H. O. K., Michot, G., Narita, H., and Suzuki, T.: Snow as a foam of ice: plasticity, fracture and the brittle-to-ductile transition, Philos. Mag. A, 81, 2161-2181, 2001.

Kwon, Y., Thornton, K., and Voorhees, P.: Coarsening of bicontinuous structures via nonconserved and conserved dynamics, Phys. Rev. E, 75, 021120, 2007.

Legagneux, L., Cabanes, A., and Domine, F.: Measurement of the specific surface area of 176 snow samples using methane adsorption at 77 K, J. Geophys. Res., 107, 4335, 2002.

Legagneux, L., Lauzier, T., Domine, F., Kuhs, W., Heinrichs, T., and Techmer, K.: Rate of decay of specific surface area of snow during isothermal experiments and morphological changes studied by scanning electron microscopy, Can. J. Phys., 81, 459-468, 2003.

Legagneux, L., Taillandier, A.-S., and Domine, F.: Grain growth theories and the isothermal evolution of the specific surface area of snow, J. Appl. Phys., 95, 6175, 2004.

Lehning, M., Bartelt, P., Brown, B., Fierz, C., and Satyawali, P.: A physical SNOWPACK model for the Swiss avalanche warning Part II. Snow microstructure, Cold Reg. Sci. Technol., 35, 147167, 2002.

Libois, Q., Picard, G., France, J. L., Arnaud, L., Dumont, M., Carmagnola, C. M., and King, M. D.: Influence of grain shape on light penetration in snow, The Cryosphere, 7, 1803-1818, 2013, http://www.the-cryosphere-discuss.net/7/1803/2013/.

Löwe, H., Spiegel, J., and Schneebeli, M.: Interfacial and structural relaxations of snow under isothermal conditions, J. Glaciol., 57, 499-510, 2011.

Löwe, H., Riche, F., and Schneebeli, M.: A general treatment of snow microstructure exemplified by an improved relation for thermal conductivity, The Cryosphere, 7, 1473-1480, 2013, http://www.the-cryosphere-discuss.net/7/1473/2013/.

Matzl, M. and Schneebeli, M.: Measuring specific surface area of snow by near-infrared photography, J. Glaciol., 52, 558-564, 2006.

McCreight, J. L. and Small, E. E.: Modeling bulk density and snow water equivalent using daily snow depth observations, The Cryosphere, 8, 521-536, 2014, http://www.the-cryosphere-discuss.net/8/521/2014/.

Michelsen, K., De Raedt, H., and De Hosson, J.: Aspects of mathematical morphology, Adv. Imag. Elect. Phys., 125, 119-194, 2003.
Perovich, D. K.: Light reflection and transmission by a temperate snow cover, J. Glaciol., 53, 201-210, 2007.

Petrenko, V. F. and Whitworth, R. W.: Physics of ice, Oxford University Press, 1999.

Pinzer, B. R. and Schneebeli, M.: Snow metamorphism under alternating temperature gradients: Morphology and recrystallization in surface snow, Geophys. Res. Lett., 36, L23503, 2009.

Schleef, S. and Löwe, H.: X-ray microtomography analysis of isothermal densification of new snow under external mechanical stress, J. Glaciol., 59, 233-243, 2013.

Schleef, S., Jaggi, M., Löwe, H., and Schneebeli, M.: An improved machine to produce nature-identical snow in the laboratory, J. Glaciol., 60, 94-102, 2014a.

Schleef, S., Löwe, H., and Schneebeli, M.: Hot pressure sintering of low density snow analyzed by X-ray microtomography and in-situ micro-compression, Acta Mater., 71, 185-194, 2014b.

Steinkogler, W., Fierz, C., Lehning, M., and Obleitner, F.: Systematic Assessment of New Snow Settlement in SNOWPACK, Proceedings of the 2009 International Snow Science Workshop, Davos, Switzerland, 132-135, 2009.

Taillandier, A.-S., Domine, F., Simpson, W. R., Sturm, M., and Douglas, T. a.: Rate of decrease of the specific surface area of dry snow: Isothermal and temperature gradient conditions, J. Geophys. Res., 112, F03003, 2007.

Thompson, G., Field, P. R., Rasmussen, R. M., and Hall, W. D.: Explicit Forecasts of Winter Precipitation Using an Improved Bulk Microphysics Scheme. Part II: Implementation of a New Snow Parameterization, Mon. Wea. Rev., 136, 5095-5115, 2008.

Vetter, R., Sigg, S., Singer, H. M., Kadau, D., Herrmann, H. J., and Schneebeli, M.: Simulating isothermal aging of snow, Europhys. Lett., 89, 26001, 2010.

Vionnet, V., Brun, E., Morin, S., Boone, A., Faroux, S., Le Moigne, P., Martin, E., and Willemet, J.-M.: The detailed snowpack scheme Crocus and its implementation in SURFEX v7.2, Geosci. Model Dev., 5, 773-791, 2012.

Wiesmann, A., Mätzler, C., and Weise, T.: Radiometric and structural measurements of snow samples, Radio Sci., 33, 273-289, 1998. 